\title{
A nonlinear model for crop development as a function of temperature
}

\author{
Xinyou Yin a, Martin J. Kropff a,b,c.*, Graham McLaren ${ }^{d}$, \\ Romeo M. Visperas ${ }^{a}$ \\ 'Agronomy, Plant Physiology' and Agroecology Division, International Rice Research Institute, P.O. Box 933 \\ Manila, Philippines \\ ${ }^{\circ}$ Depariment of Theoretical Production Ecology, Agriculsural Universiry, P.O. Box 430,6700 AK \\ Wageningen. The Netherlands \\ "DLO-Research Institule for Agrobiology and Soil Fertility (AB-DLO), P.O. Box 14, 6700 AA Wageningen. \\ The Netherlands \\ 'Biometrics Unit, International Rice Research Institute, P.O. Box 933, Manila. Philippines
}

Received 22 November 1994; accepted 9 March 1995

\section{Abstract}

The Beta function, commonly used as a skewed probability density function in statistics, was introduced to describe the effect of temperature on the rate of crop development. The framework is set by three cardinal temperatures, namely the base $\left(T_{\mathrm{b}}\right)$, the optimum $\left(T_{\mathrm{o}}\right)$ and the ceiling $\left(T_{\mathrm{c}}\right)$ temperature. The model parameters $T_{\mathrm{b}}$ and $T_{\mathrm{c}}$ and three other coefficients $\mu, \alpha$ and $\beta$ can be used to derive the value of $T_{0}$ and the maximum development rate. Parameter $\alpha$ also characterizes the curvature of the relationship with temperatures between $T_{b}$ and $T_{0}$, and parameter $\beta$ describes the curvature between $T_{0}$ and $T_{c}$. The model has one parameter less than the Rice Clock Model (RCM); and in contrast to the RCM, it ensures that the maximum development rate occurs exactly at $T_{0}$. The model accurately described the response to temperature of several developmental processes, and was superior to two widely used thermal time approaches in predicting rice flowering time.

\section{Introduction}

Crop development is primarily affected by temperature and can be modified by other factors such as photoperiod (Hodges, 1991). Within a range of temperatures below a

\footnotetext{
- Corresponding author at: Department of Theoretical Production Ecology, Agricultural University, P.O.
} Box 430, 6700 AK Wageningen, The Netherlands. 
certain value, crop development rate (DR) often increases proportionally with the temperature (Roberts and Summerfield, 1987). With the global warming due to the greenhouse effect, the effect of high temperatures on DR has also posed particular concern to modelers for predicting crop development (Matthews et al., 1995).

The effect of temperature on DR is often described by using a thermal time concept. One widely used thermal time method (Tollenaar et al., 1979) is the Growing Degree Days (GDD) procedure, which relates DR linearly to temperatures above a crop- or cultivar-specific base temperature $\left(T_{\mathrm{b}}\right)$, at or below which the DR remains zero. In some applications of the GDD procedure, an upper limit of temperature is assumed above which the DR remains constant (Hodges, 1991).

Although the GDD system is attractive because of its simplicity and its higher accuracy in predicting phenological events than number of days per se (Kiniry and Keener, 1982), it has been subjected to much criticism over the years. The classical work of Lehenbauer (1914) on the elongation of maize (Zea mays L.) seedlings in relation to temperature showed a rapid decline of the elongation rate when the optimum temperature, $T_{0}$, was exceeded. The data of Lehenbauer (1914) have been used by many studies (e.g. Gilmore and Rogers, 1958; Coelho and Dale, 1980) to describe DR of crops. For cxample, based on these data, Gilmore and Rogers (1958) presented a bilinear model (BLM) that included a reversed linear function to account for declining DR at temperatures higher than $T_{\mathrm{o}}$. Roberts and Summerfield (1987) defined the maximum temperature at which the DR equals zero as a ceiling temperature $\left(T_{\mathrm{c}}\right)$. Garcia-Huidobro et al. (1982) and Roberts and Summerfield (1987) described temperatures between $T_{b}$ and $T_{\mathrm{o}}$ as sub-optimal and those between $T_{\mathrm{o}}$ and $T_{\mathrm{c}}$ as supra-optimal; and $T_{\mathrm{b}}, T_{\mathrm{o}}$ and $T_{\mathrm{c}}$ were referred to as three cardinal temperatures.

Although the BLM describes the data of Lehenbauer (1914) better than the GDD, it does not describe the pattern accurately. The data showed a skew bell-shaped curve: an accelerating increase of the rate at low temperatures, a linear section, an optimum, followed by a rapid fall-off beyond $T_{0}$. This type of curve is qualitatively typical for the temperature response of many complex biological processes (Ferguson, 1958; Orchard, 1975: Tyldesley, 1978; Johnson and Thomley, 1985).

Various nonlinear models have been developed to describe the temperature response of developmental processes in plants. Johnson and Thornley (1985) reviewed many nonlinear equations for biological processes based on their underlying theory. A detailed model, which is based on the response of enzymatic reactions to temperature, was found to fit the data of Lehenbauer (1914) very well (Sharpe and DeMichele, 1977). However, when this model was introduced to predict maize development in the field, it did not perform better than the thermal time methods GDD and BLM (Kiniry and Keener, 1982). In addition, its large number of parameters prevented its use under field conditions (Kiniry and Keener, 1982; Hodges, 1991). Most nonlinear approaches use descriptive equations (Robertson, 1968; Coligado and Brown, 1975; Angus et al., 1981; Horie and Nakagawa, 1990; Gao et al., 1992). However, most of these descriptive equations do not account for the frequently observed decline of DR at supra-optimal temperatures (e.g. the power-law function (Coligado and Brown, 1975), the exponential equation (Angus et al., 1981) and the logistic model (Horic and Nakagawa, 1990)). A quadratic equation (c.g. Robertson, 1968) does account for this decline at supra-optimal 


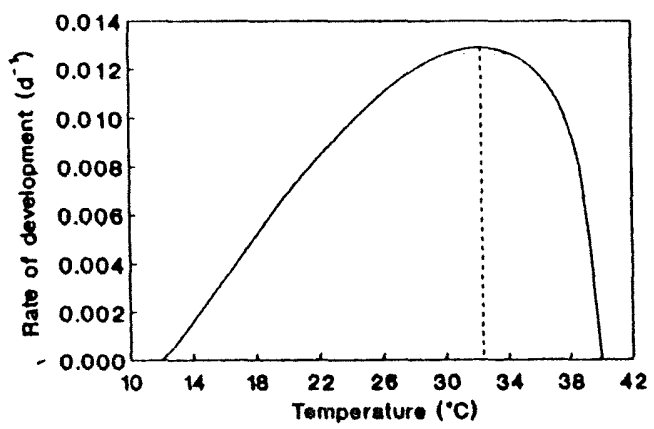

Fig. 1. Relation between temperature and rate of development from emergence to heading in rice cultivar DTWX. based on the basic equation (Eq. 1) of the Rice Clock Model (Gao et al.. 1992). The dotted line indicates the discontinuous par given by Eq. 2. Note the discrepancy between the prespecified optimum temperature $\left(30^{\circ} \mathrm{C}\right)$ and the temperature at which the rate calculated from Eq. I is maxinal (shown by the vertical dashed line).

temperatures. However, it assumes a symmetric response and does not allow for any concave curvature near $T_{\mathrm{b}}$. These limitations were overcome in the Rice Clock Model (RCM) (Gao et al., 1992), which describes the response of DR to temperature as:

$$
\mathrm{DR}=\exp (k)\left(\frac{T-T_{\mathrm{b}}}{T_{\mathrm{o}}-T_{\mathrm{h}}}\right)^{\alpha}\left(\frac{T_{\mathrm{c}}-T}{T_{\mathrm{c}}-T_{\mathrm{o}}}\right)^{\beta}
$$

where $k . \alpha$ and $\beta$ are the model parameters, and $\exp (k)$ defines the maximum DR when $T=T_{\mathrm{b}}$ (in the orginal RCM, $T_{\mathrm{b}}, T_{\mathrm{c}}, \alpha$ and $\beta$ were denoted as $T_{\mathrm{L}}, T_{11}, P$ and $Q$. respectively). However, the maximum DR does not always occur at $T_{0}$ in Eq. 1. For example, using the parameters for an indica rice cultivar DTWX as derived by Gao et al. (1992), the temperature for the maximum DR based on Eq. 1 is $2.3^{\circ} \mathrm{C}$ higher than the prespecified $T_{\mathrm{o}}$ of $30^{\circ} \mathrm{C}$ (Fig. 1). To make the model have maximum DR at $T_{0}$, Gao et al. (1992) added the following restriction:

$$
\mathrm{DR}=\exp (k) \quad \text { if }\left(\frac{T-T_{\mathrm{b}}}{T_{\mathrm{o}}-T_{\mathrm{b}}}\right)^{\alpha}\left(\frac{T_{\mathrm{c}}-T}{T_{\mathrm{c}}-T_{\mathrm{o}}}\right)^{\beta}>1
$$

However, this restriction is artificial and can result in a discontinuous nonlinear relationship (Fig. 1).

In this paper, a nonlinear model, which is simpler than the RCM but overcomes the problem of the RCM, is introduced to describe crop development involving the three cardinal temperatures. The model was evaluated using published data sets on several developmental processes, and was compared with the RCM and the two thermal time methods GDD and BLM for predicting the time to flowering of the rice crop. 
2. Materials and methods

\subsection{The model}

A well-known nonsymmetric function, the Beta function (Abramowitz and Stegun, 1965), provides a model for the relationship between DR and temperature which has a form similar to that of the RCM, Eq. 1, but has fewer parameters and allows nonproblematic estimation of $T_{0}$. The Beta function is commonly used to give a flexible family of nonsymmetric, unimodal probability density functions with fixed end points (Johnson and Leone, 1964) which allow points of inflexion on either side of the mode. Based on the Beta model, an equation for describing the response of the DR to temperatures between $T_{\mathrm{b}}$ and $T_{\mathrm{c}}$ can be expressed as:

$$
\mathrm{DR}=\exp (\mu)\left(T-T_{\mathrm{b}}\right)^{\alpha}\left(T_{\mathrm{c}}-T\right)^{\beta}
$$

where $\mu, \alpha$ and $\beta$ are the model parameters.

In contrast to the RCM, Eq. 3 does not include $T_{0}$ and the maximum DR as its parameters; however, it can provide estimates of $T_{0}$ and the maximum DR. $T_{0}$ is the zero of the first-order derivative $\mathrm{DR}^{\prime}$ of Eq. 3 which is:

$$
\mathrm{DR}^{\prime}=\exp (\mu)\left(T-T_{\mathrm{b}}\right)^{\alpha}\left(T_{\mathrm{c}}-T\right)^{\beta}\left(\frac{\alpha}{T-T_{\mathrm{b}}}-\frac{\beta}{T_{\mathrm{c}}-T}\right)
$$

Hence

$$
T_{\mathrm{o}}=\frac{\alpha T_{\mathrm{c}}+\beta T_{\mathrm{b}}}{\alpha+\beta}
$$

Substituting $T_{\mathrm{o}}$ into Eq. 3 results in an estimate of $R_{0}$, the maximum DR:

$$
R_{\mathrm{o}}=\exp (\mu) \alpha^{\alpha} \beta^{\beta}\left(\frac{T_{c}-T_{\mathrm{b}}}{\alpha+\beta}\right)^{a+\beta}
$$

Thus, the Beta model has one parameter less than the RCM; but, unlike the RCM, it can smoothly describe the nonlinear relationship between DR and temperature.

\subsection{Experimental data}

Three published experimental data sets for different crops were used to illustrate the ability of the Beta model to describe the shape of the temperature response of crop development. The first data set gives the duration between sowing and emergence in two cassava (Manihot esculenta Crantz) cultivars MAus10 and MAus7 under a range of diurnally constant temperatures (Keating and Evenson, 1979). The second data set, on meristem temperature effect on the leaf development of maize (cv. 'Erliking' F1 hybrid), was published by Watts (1971). In this experiment, the temperature of the meristematic region was varied between 0 and $40^{\circ} \mathrm{C}$, and the temperature of the root zone and the air around the leaves was kept at $25^{\circ} \mathrm{C}$. The third data set, on the development from sowing to tassel initiation of maize, was published by Ellis et al. 
Table 1

Treatments, observed days to flowering in the controlled-temperature experiment of IRRI (1977) on rice cultivar IR8, and predicted days by each of the four models: the Growing Degree Days procedure (GDD), the bilinear model (BLM), the Rice Clock Model (RCM) and the Beta model (Beta), using the parameters (presented in Fig. 5) derived from an independent experiment with five diurnally constant temperatures

\begin{tabular}{|c|c|c|c|c|c|c|c|c|}
\hline \multirow[t]{2}{*}{ Treatment No. } & \multicolumn{3}{|c|}{ Temperalure $\left({ }^{\circ} \mathrm{C}\right)^{\circ}$} & \multirow[t]{2}{*}{ Observed (d) } & \multicolumn{4}{|c|}{ Predicted (d) } \\
\hline & Day & Night & Mean & & GDD & BLM & $\mathrm{RCM}$ & Beta \\
\hline $\mathbf{a}$ & 24 & 24 & 24.0 & 98 & 100 & 100 & 99 & 99 \\
\hline b & 26 & 23 & 24.0 & 84 & 100 & 100 & 99 & 99 \\
\hline c & 28 & 22 & 24.0 & 112 & 100 & 100 & 102 & 102 \\
\hline d & 30 & 21 & 24.0 & 118 & 106 & 100 & 108 & 108 \\
\hline e & 32 & 20 & 24.0 & 1,30 & 112 & 112 & 117 & 117 \\
\hline f & 36 & 18 & 24.0 & $>155$ & 125 & 161 & 162 & 162 \\
\hline g & 32 & 18 & 22.7 & 148 & 125 & 127 & 1.37 & 1.37 \\
\hline h & 28 & 18 & 21.3 & 153 & 125 & 125 & 1.38 & 1.38 \\
\hline$i$ & 24 & 18 & 20.0 & 145 & 143 & 143 & 157 & 1.57 \\
\hline j & 20 & 18 & 18.7 & $>155$ & 167 & 167 & 19.5 & 195 \\
\hline$k$ & 24 & 22 & 22.7 & 106 & 112 & 112 & 112 & 112 \\
\hline 1 & 24 & 20 & 21.3 & 129 & 125 & 125 & 131 & 131 \\
\hline
\end{tabular}

" In the experiment of IRRI (1977), durations of day and night temperatures were $8 \mathrm{~h}$ and $16 \mathrm{~h}$ per day. respectively.

(1992). In this experiment, plants of five cultivars (Tuxpeno Crema I C 18, Cravinhos $8445, \mathrm{~B} 73 \times \mathrm{Mo17}, \mathrm{H}-32$, and Across 8201) were grown in growth chambers with 10 diurnally constant temperatures ranging from 12 to $37^{\circ} \mathrm{C}$ at a photoperiod of $12 \mathrm{~h} \mathrm{~d}^{-1}$.

A fourth data set was used to compare the predictive capacity of the Beta model with the RCM and two widely-used thermal time methods GDD and BLM. This data set was obtained from a phytotron experiment on the effect of temperature on days from sowing to flowering in rice (Oryza sativa L.) cultivar IR8 (IRRI, 1977). Treatments in the experiment included one diurnally constant temperature $\left(24^{\circ} \mathrm{C}\right)$ and 11 diurnally alternating regimes with different day and night temperatures (Table 1). In all alternating temperature treatments. the day temperature was applied for $8 \mathrm{~h} \mathrm{~d}^{-1}$ and the night temperature for $16 \mathrm{~h} \mathrm{~d}^{-1}$. The four models were parameterized using independent data for IR8 from an experiment conducted in 1993 with five diurnally constant temperatures $22,24,26,28$ and $32^{\circ} \mathrm{C}$ at a photoperiod of $12 \mathrm{~h} \mathrm{~d}^{-1}$ (Yin and Kropff, unpublished data, 1993). Days to flowering at the common constant temperature treatment of $24^{\circ} \mathrm{C}$ were $98 \mathrm{~d}$ in the IRRI (1977) experiment and $97 \mathrm{~d}$ in the 1993 data set, indicating that the effective photoperiod was compatible between these two experiments.

\subsection{Analytical approaches}

When values of $T_{\mathrm{b}}$ and $T_{\mathrm{c}}$ were given, the parameter values were determined by least squares regression after log-transforming Eq. 3 into its linear form:

$$
\ln \mathrm{DR}=\mu+\alpha \ln \left(T-T_{\mathrm{b}}\right)+\beta \ln \left(T_{\mathrm{c}}-T\right)
$$

Otherwise the nonlinear optimization package PROC NLIN of the Statistical Analysis Systems Institute (SAS, 1988) was used to estimate parameter values when $T_{b}$ and $T_{c}$ were not given. The SAS procedure was also used to parameterize Eq. 1 of the RCM. 
However, observations at only five temperatures in the 1993 data set for cv. IR8 of rice were not enough to estimate the six parameters in Eq. 1. Because the models were evaluated using data from phytotron experiments of IRRI (1977) where the temperatures were not close to the extremes of $T_{\mathrm{b}}$ and $T_{\mathrm{c}}$, the model performance might not be very sensitive to the values for $T_{\mathrm{b}}$ and $T_{\mathrm{c}}$. To reduce the number of parameters to be estimated, values for $T_{\mathrm{b}}$ and $T_{\mathrm{c}}$ were predefined for the RCM and the Beta model based on sensitivity analysis by varying $T_{\mathrm{b}}$ and $T_{\mathrm{c}}$ within an adequate range.

To compare the performance of the models in predicting rice flowering, the mean absolute deviation (MD) was used to indicate the accuracy of the predictions. All models were run with an 8-h time step to account for the difference in the duration of day and night temperatures in the data set of IRRI (1977).

\section{Results}

\subsection{Illustration of the descriptive ability of the Beta model}

Keating and Evenson (1979) showed that cassava plants of MAus10 did not emerge below $14.8^{\circ} \mathrm{C}$ or above $36.6^{\circ} \mathrm{C}$, whereas MAus7 did not emerge below $12.5^{\circ} \mathrm{C}$ or above $39.8^{\circ} \mathrm{C}$. From these observations, values of $T_{b}$ and $T_{c}$ for the two cultivars were determined. Values for the other parameters of the Beta model were estimated by least squares regression of log-transformed data (Table 2). The model described the shape of the response quite accurately, although the DR of MAus7 around $T_{0}$ was somewhat underestimated (Fig. 2). The results indicate that the nonlinear response is not symmetric.

In the data of Watts (1971) on meristem temperature effect on maize leaf development, no distinct value for either $T_{\mathrm{b}}$ or $T_{\mathrm{c}}$ was determined. All five parameters of the Beta model were then obtained from the nonlinear optimization package of SAS. The model adequately described the data (Table 2 and Fig. 3). The relatively low value for $T_{\mathrm{b}}$ can be explained by the fact that the temperature of air and root-zone was kept at $25^{\circ} \mathrm{C}$ which may have been high enough to trigger maize leaf extension even though the meristem temperature was below $0^{\circ} \mathrm{C}$. However, this estimation for $T_{b}$ was based on extrapolation far beyond the range of temperatures used in the experiment, resulting in a high standard error (Table 2). Watts (1971) fitted the data between 0 and $30^{\circ} \mathrm{C}$ with an exponential curve using a $Q_{10}$ of 2.0 , a factor by which the rate is increased as temperature rises $10^{\circ} \mathrm{C}$. That approach does not account for the rapid decline of the rate above $T_{\mathrm{o}}$ (Fig. 3).

Ellis et al. (1992) indicated that the value of $T_{c}$ for maize cvs. H-32 and Across 8201 was about $37^{\circ} \mathrm{C}$ based on their experimental results that plants of these two cultivars grown at the constant temperature $37^{\circ} \mathrm{C}$ died before reaching tassel initiation whereas $37^{\circ} \mathrm{C}$ was not lethal to plants of other three cultivars. Based on these, the value of DR at $37^{\circ} \mathrm{C}$ for each of $\mathrm{H}-32$ and Across 8201 was determined. The Beta model closely described the nonsymmetric temperature response for rate of development between sowing and tassel initiation in the five cultivars (Fig. 4). A clear varietal difference in 
Table 2

$\checkmark$ alues of the five parancters (with standard errors in parentheses) in the Beta model (Eq. 3) estimated frum different data sets, and the resultant estimates of the optimum temperature $\left(T_{0}\right)$ and the maximum developnent rate $\left(R_{0}\right)$

\begin{tabular}{|c|c|c|c|c|c|c|c|c|c|}
\hline \multirow[t]{2}{*}{ Cultivar } & \multicolumn{5}{|c|}{ Model Paranneters } & \multirow[t]{2}{*}{$n^{2}$} & \multirow[t]{2}{*}{$r^{2 h}$} & \multirow[t]{2}{*}{$T_{n}$} & \multirow[t]{2}{*}{$R_{\mathrm{n}}$} \\
\hline & $\mu$ & $\boldsymbol{\alpha}$ & $\beta$ & $T_{\mathrm{b}}$ & $T_{\mathrm{c}}$ & & & & \\
\hline \multicolumn{10}{|c|}{ (a) Cassala (sowing-emergence)" } \\
\hline MAus $10^{\circ}$ & $\begin{array}{c}-6.484 \\
(0.301)\end{array}$ & $\begin{array}{l}1.071 \\
(0.066)\end{array}$ & $\begin{array}{l}0.469 \\
(0.070)\end{array}$ & 14.8 & 36.6 & 7 & 0.997 & 30.0 & 0.068 .3 \\
\hline MAus $7^{\circ}$ & $\begin{array}{l}-11.035 \\
(0.813)\end{array}$ & $\begin{array}{l}2.077 \\
(0.179)\end{array}$ & $\begin{array}{l}1.268 \\
(0.159)\end{array}$ & 12.5 & 39.8 & 9 & 0.975 & 29.5 & 0.1118 \\
\hline \multicolumn{10}{|l|}{ (b) Maize leaf extension ${ }^{d}$} \\
\hline Erliking & $\begin{array}{c}-9.683 \\
(7.100)\end{array}$ & $\begin{array}{l}2.56 .3 \\
(1.570)\end{array}$ & $\begin{array}{l}0.132 \\
(0.163)\end{array}$ & $\begin{array}{l}-12.8 \\
(14.8)\end{array}$ & $\begin{array}{l}40.1 \\
(0.01)\end{array}$ & 7 & 0.998 & 37.5 & 16118 \\
\hline \multicolumn{10}{|c|}{ (c) Maize (sowing-tassel initiation) d } \\
\hline Tuxpeno Crema I C 18 & $\begin{array}{c}-4.876 \\
(0.288)\end{array}$ & $\begin{array}{l}0.504 \\
(0.070)\end{array}$ & $\begin{array}{l}0.207 \\
(0.043)\end{array}$ & $\begin{array}{l}11.0 \\
(0.4)\end{array}$ & $\begin{array}{l}37.1 \\
(0.07)\end{array}$ & 10 & 0.994 & 29.5 & 0.0504 \\
\hline Cravinhos 8445 & $\begin{array}{c}-5.74 .3 \\
(0.768)\end{array}$ & $\begin{array}{l}0.754 \\
(0.189)\end{array}$ & $\begin{array}{l}0.308 \\
(0.085)\end{array}$ & $\begin{array}{l}9.7 \\
(1.4)\end{array}$ & $\begin{array}{l}37.2 \\
(0.21)\end{array}$ & 10 & 0.990 & 29.2 & 0.0573 \\
\hline $\mathrm{B} 73 \times \mathrm{Mol} 7$ & $\begin{array}{l}-5.31 .3 \\
(0.598)\end{array}$ & $\begin{array}{l}0.651 \\
(0.148)\end{array}$ & $\begin{array}{l}0.233 \\
(0.070)\end{array}$ & $\begin{array}{l}10.1 \\
(1.1)\end{array}$ & $\begin{array}{l}37.2 \\
(0.16)\end{array}$ & 10 & 0.990 & 30.0 & 0.0546 \\
\hline$H-32$ & $\begin{array}{l}-4.941 \\
(0.286)\end{array}$ & $\begin{array}{l}0.290 \\
(0.058)\end{array}$ & $\begin{array}{l}0.482 \\
(0.064)\end{array}$ & $\begin{array}{l}11.8 \\
(0.2)\end{array}$ & $\begin{array}{l}37.0 \\
(0.01)\end{array}$ & 10 & 0.990 & 21.2 & 0.0518 \\
\hline Across 8201 & $\begin{array}{c}-5.366 \\
(0.726)\end{array}$ & $\begin{array}{l}0.398 \\
(0.160)\end{array}$ & $\begin{array}{l}0.530 \\
(0.137)\end{array}$ & $\begin{array}{l}11.3 \\
(0.9)\end{array}$ & $\begin{array}{l}37.0 \\
(0.02)\end{array}$ & 10 & 0.965 & 22.3 & 0.050 .5 \\
\hline
\end{tabular}

- $n$ is the number of environments fined

" $\mathrm{r}^{2}$ is for least squares regression in cassava, and for the simple linear regression between values of observed and calculated by the model in maize (see texi).

${ }^{c} T_{\mathrm{b}}$ and $T_{\mathrm{c}}$ were detenmined as temperatures at which the cassava plants did not emerge

Data source: (a) Keating and Evenson (1979); (b) Watts (1971); (c) Ellis et al. (1992).

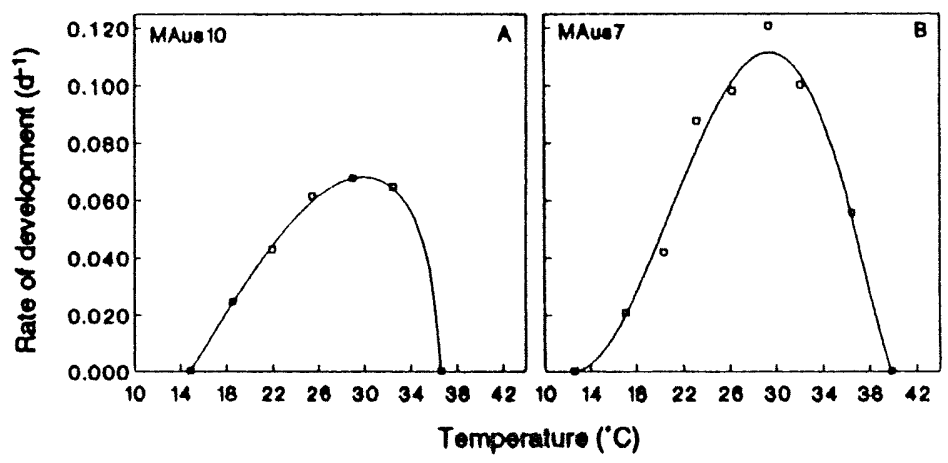

Fig. 2. Rate of development from sowing to emergence in two cassava cultivars as a function of temperature (data of Keating and Evenson. 1979). Fitted curves were derived from Eq. 3 with parameter values as in Table 2 . 


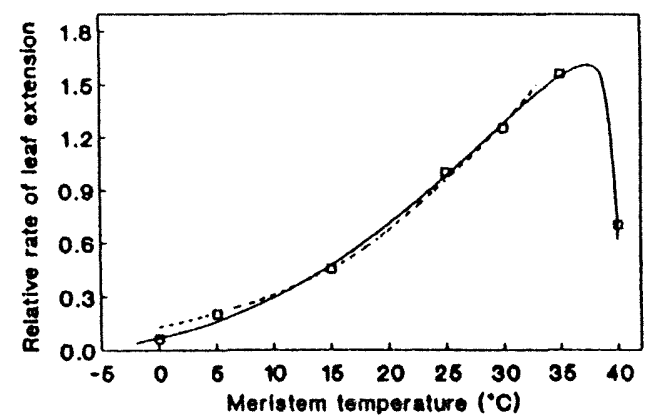

Fig. 3. Relative leaf extension rate in maize as affected by temperature at the meristem region (data of Watts, 1971). The solid curve was based on Eq. 3 with parameter values in Table 2, while the dashed one was drawn from the concept of $Q_{11}$ of 2.0 used by Watts (1971).

the $T_{\mathrm{o}}$ was found to range from 21.2 to $30.0^{\circ} \mathrm{C}$, whereas the varietal difference in either $T_{\mathrm{b}}$ or $T_{\mathrm{c}}$ was quite small (Table 2). Ellis et al. (1992) fitted the data of each cultivar by the equation $\mathrm{DR}=a+b T+c T^{2}+d T^{3}$ (where $a, b, c$ and $d$ are constants), for the sub-optimal and supra-optimal ranges separately. They indicated the problem of determining a value for $T_{\mathrm{o}}$ by visual examination of the data, as the observed $T_{\mathrm{o}}$ often did not represent a specific value or even a narrow range (e.g. Fig. 4(C)). Eq. 3 can be used to explicitly estimate $T_{\mathrm{o}}$ for each cultivar.

\subsection{Comparison of the Beta model with $G D D, B L M$, and RCM in predictive capability}

\section{Parameters of the models}

From sensitivity analysis by varying $T_{b}$ from 5 to $15^{\circ} \mathrm{C}$ and $T_{c}$ from 35 to $45^{\circ} \mathrm{C}$ in $1^{\circ} \mathrm{C}$ steps, it was established that the values of $T_{\mathrm{b}}$ and $T_{\mathrm{c}}$ had little impact on goodness of fit of both the RCM and the Beta model to the 1993 data set on the development to nowering in rice cultivar IR8. The $R^{2}$ value varied from 0.98 when $T_{\mathrm{b}}=5$ and $T_{\mathrm{c}}=35^{\circ} \mathrm{C}$ to 0.97 when $T_{\mathrm{b}}=15$ and $T_{\mathrm{c}}=45^{\circ} \mathrm{C}$ for both models. For each set of $T_{\mathrm{b}}$ and $T_{\mathrm{c}}$ values, the two models had the same $R^{2}$ value, indicating that one extra parameter in the RCM compared to the Beta model did not result in a higher descriptive ability. Since the $R^{2}$ value of both models hardly changed within a wide range of values for $T_{\mathrm{b}}$ and $T_{c}$, we selected 8 and $42^{\circ} \mathrm{C}$ as values for $T_{b}$ and $T_{c}$. These values are commonly used in rice crop growth simulation models (Alocilja and Ritchie, 1991; Kropff et al., 1994).

Based on visual inspection of the data, $28^{\circ} \mathrm{C}$ was assumed as the upper temperature $\left(T_{\mathrm{u}}\right)$ for the GDD model above which the DR remains constant, and $32^{\circ} \mathrm{C}$ was assumed to be supra-optimal for the BLM model. Parameters for the range with the increasing DR in both GDD and BLM were then estimated by linear regression on the observations at $22,24,26$ and $28^{\circ} \mathrm{C}$. For the supra-optimal range of the BLM, parameter values were estimated assuming that $T_{\mathrm{c}}=42^{\circ} \mathrm{C}$.

The parameter values for the four models, including the maximum DR $\left(R_{0}\right)$ estimated by each model, are given in Fig. 5 . All models described the data quite 


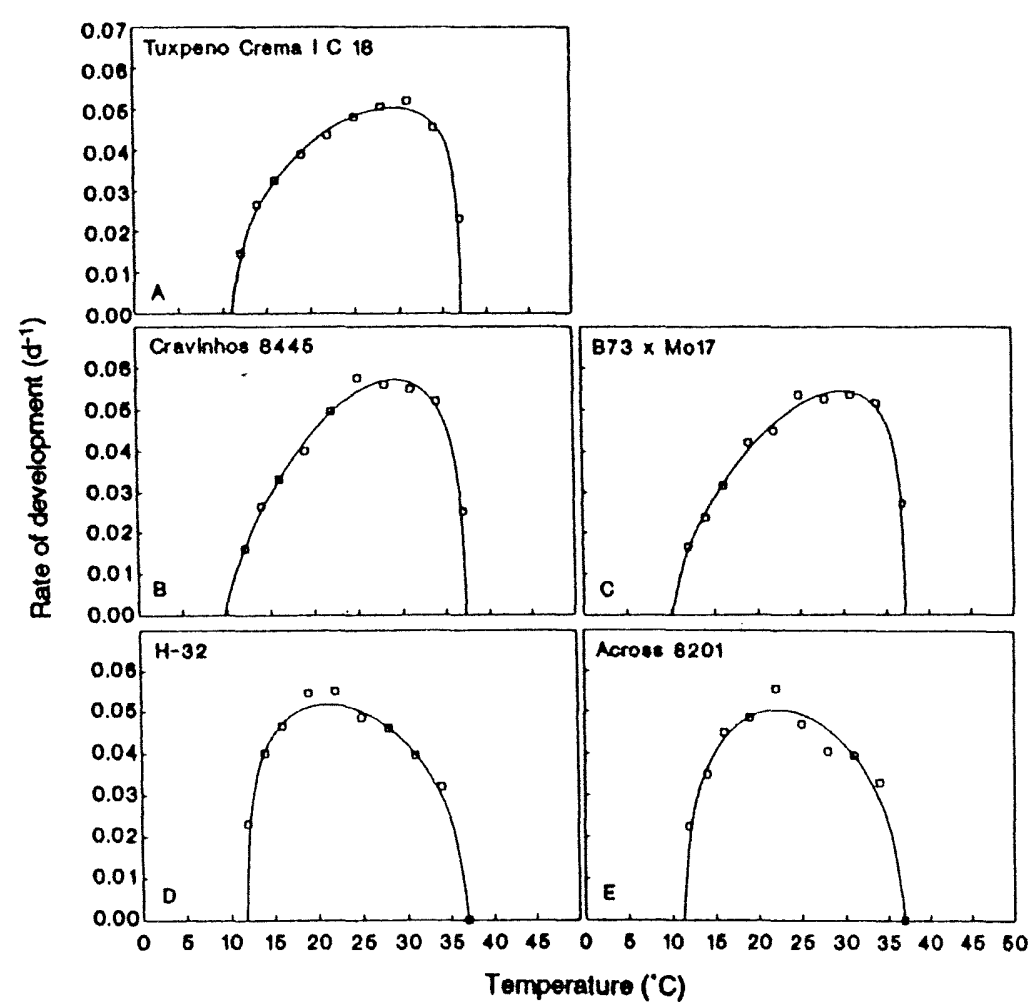

Fig. 4. Relations between temperature and the rate of development from sowing to tassel initiation in five maize cultivars at a photoperiod of $12 \mathrm{~h} \mathrm{~d}^{-1}$ (data of Ellis et al., 1992). The curves represent the relations of Eq. 3 with parameters shown in Table 2.

accurately. The estimated maximum DR was highest in the BLM and lowest in the GDD model. The temperature for the maximum DR calculated from Eq. 1 of the RCM was $30.2^{\circ} \mathrm{C}$, only $0.8^{\circ} \mathrm{C}$ higher than the generated value of $T_{0}$; so the discontinuous part of the RCM given by Eq. 2 is not obvious in Fig. 5(C).

\section{Performance of the models}

Observed and predicted days to flowering are given in Table 1. The predicted days to flowering were exactly the same for the RCM and the Beta model. The comparisons between observed and predicted days to flowering for the four models are shown in Fig. 6. This figure does not include results of the regimes $36 / 18$ and $20 / 18^{\circ} \mathrm{C}$, at which observed days to flowering were recorded as $>155 \mathrm{~d}$. The nonlinear models performed hetter than the linear ones. The MD values were $12.3 \mathrm{~d}$ for the GDD, $12.7 \mathrm{~d}$ for the BLM and $9.4 \mathrm{~d}$ for the two nonlinear models (Fig. 6). 


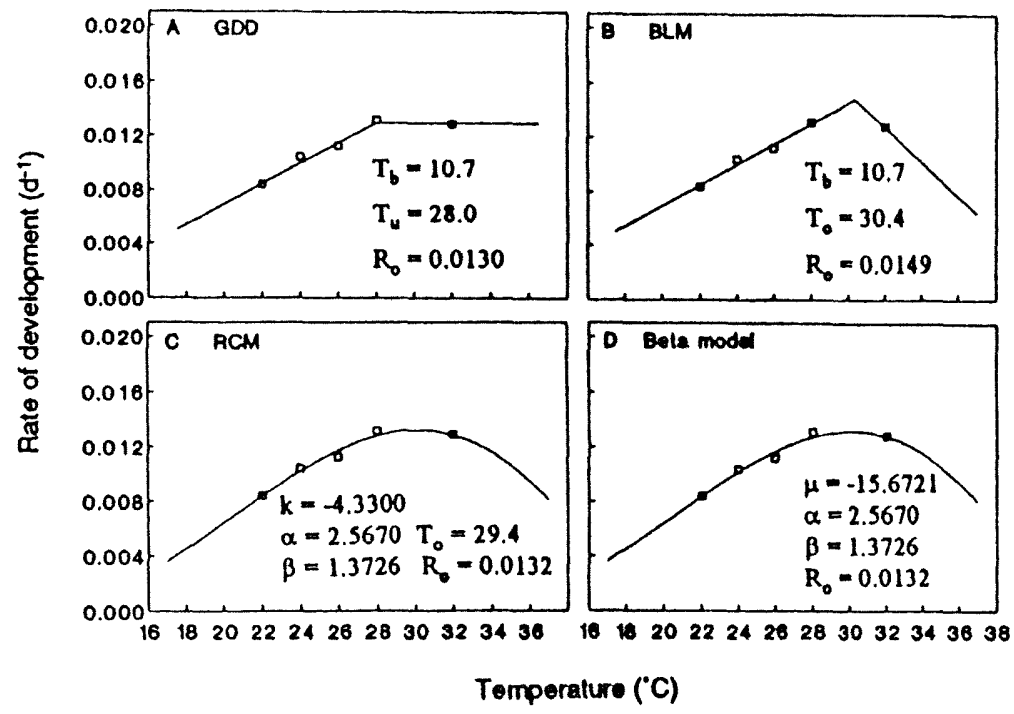

Fig. 5. Rate of development from sowing to flowering of rice (cv. IR8) at five diumally constant temperatures ( $Y$ 'in and Kropff, unpublished data, 1993), fitted respectively by the Growing Degree Days procedure (GDD), the bilinear model (BLM), the Rice Clock Model (RCM), and the Beta model. Values for $T_{\mathrm{b}}$ and $T_{\mathrm{c}}$ used in both RCM and the Beta model were 8 and $42^{\circ} \mathrm{C}$, respectively.

All models correctly predicted no flowering at 155 days for the regime of $20 / 18^{\circ} \mathrm{C}$. However, the GDD model, which does not allow for the detrimental effect of high tempcratures, overestimated the development rate at $36 / 18^{\circ} \mathrm{C}$ (Table 1). Because the

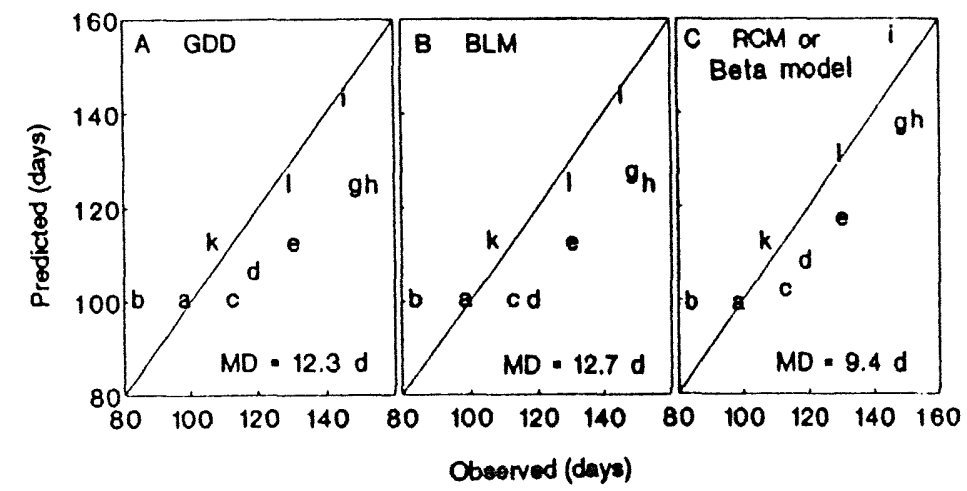

Fig. 6. Observed vs. predicted days from sowing to flowering of rice (cv. IR8) (data of IRRI, 1977) for the four models. The predicted values were based on the parameters derived from an independent experiment with five diurnally constant temperalures (presented in Fig. 5). The letters comespond to the treatment numbers specified in Table 1 . The solid line represents the $1: 1$ ratio. MD is the mean absolute derivation of predictions from the observed days. 
DR was assumed to he constant for $T>T_{u}$, the GDD model also failed to predict the actual difference in the flowering date among $28 / 18,32 / 18$ and $36 / 18^{\circ} \mathrm{C}$ treatments. However, the MD value for the GDD model was somewhat lower than that for the BLM (Fig. 6). This was because the BLM tended to overestimate the DR at temperatures close to $T_{\mathrm{o}}$ (Fig. 5), so the BLM underestimated days to flowering at $30 / 21^{\circ} \mathrm{C}$ (Table 1 ).

The superiority of the nonlinear models was particularly obvious for the $28 / 22$, $30 / 21,32 / 20,32 / 18$ and $28 / 18^{\circ} \mathrm{C}$ treatments, where the night temperature was relatively low. For these regimes, days to flowering were considerably underestimated by the linear models. This can he attributed to the fact that development rates at temperatures $<22^{\circ} \mathrm{C}$ were somewhat higher for the linear models than the nonlincar ones (Fig. 5).

A clear problem with the linear models is their inability to predict the observed difference in the flowering date between the treatments with the same average daily temperature of $24^{\circ} \mathrm{C}$ but with different diurnal amplitudes. The GDD model had the same prediction for these treatments where the day temperature was lower than $T_{u}$, whilc the BLM had the same prediction for those where the day temperature was sub-optimal (Table 1). Actual difference in the flowering date among these treatments was predicted by the two nonlinear models to some extent. A similar result also occurred for the comparison between $28 / 18$ and $24 / 20^{\circ} \mathrm{C}$, which had the same mean daily value as $21.3^{\circ} \mathrm{C}$.

\section{Discussion}

\section{I. Model performance}

The thermal time approaches are often used to describe the effect of temperature on crop development, hecause the relationship between development and temperature hecomes linear over a wide range of temperatures once the rate (inverse of the duration) is used (Roherts and Summerficld, 1987). However, evidence from several experiments showed that the rate also responds to temperature in a nonlinear way (e.g. Fig. 4). The two widely used thermal time methods GDD and BLM did not predict rice flowering dates as accurately as the (wo nonlinear models (Table 1 and Fig. 6). Hodges (1991) emphasized that a linear equation has to be reparameterized for applications outside the range of conditions for which the parameters were derived. However. this may result in different estimates of $T_{\mathrm{h}}$ for the same cultivar. For example, based on a linear function. Summerfield et al. (1992) reported that $T_{\mathrm{b}}$ for the development to panicle emergence in rice cultivar IR36 was $10.9^{\circ} \mathrm{C}$, whereas Ellis et al. (1993) reported a $T_{\mathrm{b}}$ of $8.6^{\circ} \mathrm{C}$ for this cultivar. This is most probably due to the fact that temperatures used by Summerficld et al. (1992) included lower regimes than those used by Ellis et al. (1993).

\subsection{Relationships between the Beta model and the RCM}

Several nonlinear models have been developed to quantify the response of crop development to temperature (Rohertson, 1968; Coligado and Brown, 1975; Angus et al., 
1981: Horie and Nakagawa, 1990; Gao et al., 1992). The RCM (Gao et al., 1992) shows some advantages over others, since it is flexible enough to handle nonsymmetric responses. However, the basic equation of the RCM, Eq. 1, does not necessarily predict a maximum DR at the predetermined $T_{0}$ (Fig. 1). Gao et al. (1992) attempted to overcome this problem by adding the restriction of Eq. 2, which, however, can make the RCM take a discontinuous form. By setting the first-order derivative of Eq. I equal to zero:

$$
\mathrm{DR}^{\prime}=\exp (k)\left(\frac{T-T_{\mathrm{b}}}{T_{\mathrm{o}}-T_{\mathrm{b}}}\right)^{\alpha}\left(\frac{T_{\mathrm{c}}-T}{T_{\mathrm{c}}-T_{\mathrm{o}}}\right)^{\beta}\left(\frac{\alpha}{T-T_{\mathrm{b}}}-\frac{\beta}{T_{\mathrm{c}}-T}\right)=0
$$

an expression for calculating $T_{\mathrm{o}}$ in the unconstrained RCM is derived; and this expression is the same as Eq. 5. Substituting this expression for $T_{0}$ into Eq. 1 leads to a form of the Beta model similar to Eq. I, but equivalent to Eq. 3:

$$
\mathrm{DR}=\exp \left(k^{*}\right)\left(\frac{T-T_{\mathrm{b}}}{T_{\mathrm{c}}-T_{\mathrm{b}}}\right)^{\alpha}\left(\frac{T_{\mathrm{c}}-T}{T_{\mathrm{c}}-T_{\mathrm{b}}}\right)^{\beta}
$$

where $k^{*}=k+\alpha \ln ((\alpha+\beta) / \alpha)+\beta \ln ((\alpha+\beta) / \beta)$. The form of the Beta model given in Eq. 3 results from placing the terms in $\left(T_{c}-T_{b}\right)$ of Eq. 8 in the constant, $\mu$, so that $\mu=k^{*}-(\alpha+\beta) \ln \left(T_{\mathrm{c}}-T_{\mathrm{b}}\right)$. On the other hand, substituting expressions for $\alpha$ or $\beta$ from Eq. 5 into Eq. 1 produces the Beta model in two other forms':

$$
\mathrm{DR}=\exp (k)\left[\left(\frac{T-T_{\mathrm{b}}}{T_{\mathrm{o}}-T_{\mathrm{b}}}\right)^{\frac{T_{\mathrm{o}}-T_{\mathrm{h}}}{T_{\mathrm{c}}-T_{\mathrm{o}}}}\left(\frac{T_{\mathrm{c}}-T}{T_{\mathrm{c}}-T_{\mathrm{o}}}\right)\right]^{\beta}
$$

and

$$
\mathrm{DR}=\exp (k)\left[\left(\frac{T-T_{\mathrm{b}}}{T_{\mathrm{o}}-T_{\mathrm{b}}}\right)\left(\frac{T_{\mathrm{c}}-T}{T_{\mathrm{c}}-T_{\mathrm{o}}}\right)^{\frac{T_{\mathrm{c}}-T_{\mathrm{o}}}{T_{\mathrm{o}}-T_{\mathrm{b}}}}\right]^{\alpha}
$$

Clearly, $T_{0}$, or $\alpha$, or $\beta$ in Eq. 1 of the RCM is superfluous; dropping one of them results in the Bcta model. The RCM gives similar or identical estimates of DR to the Beta model when the difference between predetermined $T_{0}$ and the calculated $T_{0}$ from the constraint of Eq. 7 is small Table 1). However, this difference can be large in which case the Beta model will give a more reliable description than the RCM.

\subsection{Flexibility of the Beta model}

Although the Beta model has one parameter less than Eq. I of the RCM, it has the same property as Eq. I, that is, both low and high temperature effects have been

\footnotetext{
'Note added in proof. The equations for development rate presented here assume a unit for development rate To make the unit explicit it is better to replace the factor $\exp (k)$ in Eq. $8 \mathrm{~b}$ or Eq. $8 \mathrm{c}$ by the factor $R_{0}$. which tands for the rate at optimum temperature. $T_{0}$. This rate is not dimensionless and could be expressed as development units per day, or in another case as $\mathrm{mm}$ per day. Future users should be aware of this implied unit.
} 


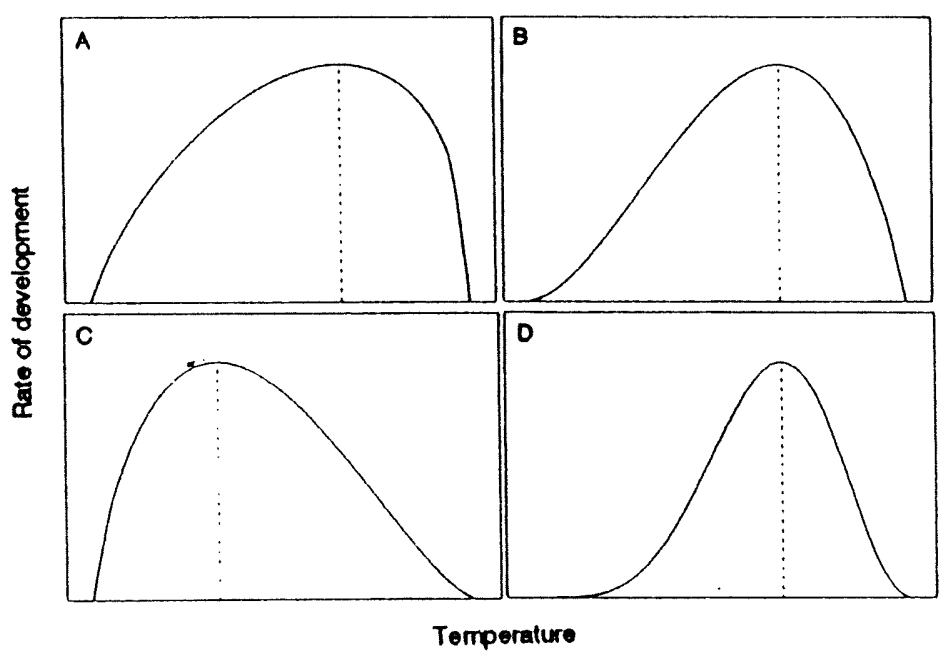

Fig. 7. Four theoretical nonsymmetric forms of the nonlinear curve for the temperature response of development rate as determined by parameters $\alpha$ and $\beta$ in the Beta model: (A) $\alpha<1$ and $\beta<1$, no inflexion within both sub-optimal and supra-optimal ranges: (B) $\alpha>1$ but $\beta<1$, an inflexion with the sub-optimal range but no inflexion within the supra-optimal range: (C) $\alpha<1$ but $\beta>1$. no inflexion with the sub-optimal range but an inflexion within the supra-optimal range: (D) $\alpha>1$ and $b>1$, an inflexion within each of sub-optimal and supra-optimal ranges.

considered in a single equation, and the nonsymmetric response can be flexibly handled (Figs. 2-4). The flexibility of the Beta model is illustrated by the fact that the model can describe any inflexion of response in the sub-optimal or supra-optimal range. The temperatures at which the inflexion occurs can be calculated as the values at which the second-order derivative equals zero. These values can be derived as:

$$
\begin{aligned}
& T_{\mathrm{f} 1}=\frac{\alpha T_{\mathrm{c}}+\beta T_{\mathrm{b}}}{\alpha+\beta}-\frac{T_{\mathrm{c}}-T_{\mathrm{b}}}{\alpha+\beta} \sqrt{\frac{\alpha \beta}{\alpha+\beta-1}} \\
& T_{\mathrm{f} 2}=\frac{\alpha T_{\mathrm{c}}+\beta T_{\mathrm{b}}}{\alpha+\beta}+\frac{T_{\mathrm{c}}-T_{\mathrm{b}}}{\alpha+\beta} \sqrt{\frac{\alpha \beta}{\alpha+\beta-1}}
\end{aligned}
$$

where $T_{\mathrm{fl}}$ and $T_{\mathrm{f}}$ represent the temperatures of the inflexion points located respectively at the sub-optimal and supra-optimal range. Eq. 9 showed that $T_{\mathrm{fl}}=T_{\mathrm{b}}$ if $\alpha=1$, whereas Eq. 9 shows that $T_{\mathrm{f}}=T_{\mathrm{c}}$ if $\beta=1$. It can be further analyzed that an inflexion occurs in the sub-optimal range only if $\alpha>1$ (Fig. 2(B), Fig. 3), and an inflexion occurs in the supra-optimal range only if $\beta>1$ (Fig. 2(B)). Parameter $\alpha$, therefore, determines the curvature of the relationship over the sub-optimal range, whereas parameter $\beta$ determines the curvature in the DR at supra-optimal temperatures. Different combinations of values for parameters $\alpha$ and $\beta$ make the model flexible to fit four possible nonsymmetric forms of the relationship between the DR and temperature (Fig. 7). 
In addition, some of the existing models can be generated from the Beta model. For example, the Beta model becomes a simple linear thermal time model if $\alpha=1$ and $\beta=0$, a power-law model if $\beta=0$, a quadratic model if $\alpha=\beta=1$, or a general symmetric model if $\alpha=\beta$.

\subsection{Application of the Beta model and the need for further studies}

Although the Beta model was introduced to describe the temperature response of crop development, it may apply to other biological processes. For example, according to the data of Tanaka (1976), effects of temperature on rice photosynthesis rate can be described by it. Many thermal response patterns, as presented by Ferguson (1958), Orchard (1975), Tyldesley (1978), and Johnson and Thornley (1985), coincide with the different forms of the model shown by Fig. 7. The model can be easily parameterized since it can be linearized if values of $T_{b}$ and $T_{c}$ are predetermined from the data or external sources.

For application to crop development processes, this study indicates that the model describes the response to constant temperatures quite well (Figs. 2-4). For the response to alternating temperatures, however, the mean deviation between observed and predicted days to flowering in rice was about $9 \mathrm{~d}$ (Fig. 6). In the present study, no difference in the effect of day and night temperature on crop development was assumed. With the data on IR8 rice (Table 1), however, IRRI (1977) indicated independent effects of day and night temperatures and a relatively more important role of night temperature than the day value. But this conclusion was made based on a linear model which did not realistically describe DR-temperature relationship. The greater influence of night temperature can be due to the fact that in the experiment of IRRI (1977), night temperature. was in the range where DR increases proportionally with the temperature whereas day temperature was often supra-optimal (Table 1). Nevertheless, Coligado and Brown (1975) indicated an effect of diurnal temperature range on the development in maize. As the Beta model tends to have a larger discrepancy for the treatments with a higher diurnal amplitude (Table 1), the approach might be improved by accounting for the effect of the diurnal temperature range. This gives an element that needs further study.

\section{Acknowledgements}

We thank Dr. B.S. Vergara for providing data of rice from an annual report of IRRI. We also express our appreciation to Drs. R.B. Matthews, J. Goudriaan and R.H. Ellis for their helpful review of an earlier draft of this paper.

\section{References}

Abramowitz. M. and Stegun, 1.A., 1965. Handbook of mathematical functions with formulas, graphs, and mathematical tables. Dover Publications, Inc., New York, 1045 pp.

Alocilja. E.C. and Ritchie. J.T., 1991. A model for the phenology of rice. In: T. Hodges (Editor), Predicting crop phenology. CRC Press, Boca Raton, FL. pp. 181-190. 
Angus, J.F. Mackenzie, D.H., Morton. R. and Schafer, C.A., 1981. Phasic development in field crops. II. Thermal and photoperiodic responses of spring wheat. Field Crops Res., 4: 269-283.

Coelho, D.T. and Dale, R.F., 1980. An energy-crop growth variable and temperature function for predicting com growth and development: Planting to silking. Agron. J., 72: 503-510.

Coligado, M.C. and Brown, D.M., 1975. A bio-photo-thermal model to predict tassel-initiation time in corn (Zea mays L.). Agric. Mcteorol., 15: $11-31$.

Ellis, R.H., Qi. A., Summerfield, R.J. and Roberts, E.H., 1993. Rates of leaf appearance and panicle development in rice (Oryza sativa L.): a comparison at three temperatures. Agric. For. Meteorol., 66: $129-138$.

Ellis, R.H., Summerfield, R.J., Edmeades, G.O. and Roberts, E.H., 1992. Photoperiod, temperature, and the interval from sowing to tassel initiation in diverse cultivars of maize. Crop Sci., 32: 122.5-1232.

Ferguson. J.H.A.. 19.58. Emipirical estimation of thermoreaction curves for the rate of development. Euphytica, 7: $140-146$.

Gao, L.Z., Jin. Z.Q., Huang. Y. and Zhang. L.Z., 1992. Rice clock model-a computer simulation nodel of rice development. Agric. For. Meteorol., 60: 1-16.

Garcia-Huidobro, J.. Monteith, J.L. and Squire, G.R., 1982. Time, temperature and germination of pearl millet (Pennisetum Yyphides S. and H.). I. Constant temperature. J. Exp. Bot.. 33: 288-296.

Gilmore, E.C. and Rogers, J.S.. 1958. Heat units as a method of measuring maturity in corn. Agron. J., 50: $611-615$.

Hodges. T.. 1991. Temperature and water stress effects on phenology. In: T. Hodges (Editor). Predicting crop phenology. CRC Press, Boca Raton. FL. pp. 7-13

Horie, T. and Nakagawa. H. 1990). Modelling and prediction of developnent process in rice. I. Structure and method of parameter estimation of a model for simulating development process toward heading. Jph. J. Crop Sci. 59: $1187-695$.

IRRI (Intcrnational Rice Research Institute). 1977. Annual report for 1976. Los Baños. Philippines, pP $11,3-120$.

Johnson. IR. and Thomley, J.H.M. 198.5. Temperature dependence of plant and crop processes. Ann. But.. 5.5: $1-24$

Johnson. NL. and Leone, F.C. 1964. Statistics and experimental design in engineering and the physical sciences. Vol. 1. John Wilcy and Sons. Inc., New York. 523 pp.

Keating, B.A. and Evenson, J.P. 1979. Effect of soil temperature on sprouting and sprout elongation of stem cuttings of cassava (Munihot esculenta Crantz). Field Crops Res., 2: 241-251.

Kiniry, J.R. and Keener, M.E., 1982. An enzyme kinctic equation to estimate maize development rates. Agron. J., $74: 115-119$

Kropff, M.J., Van Laar, H.H. and Matthews, R.B., 1994. ORYZAI. An ecophysiological model for irrigated rice production. SARP Research Proceedings. IRRI, Los Baños, Philippines. $110 \mathrm{pp}$

Lehenbauer. P.A.. 19/4. Growth of maize seedlings in relation to temperature. Physiol. Res.. 1: 247-288

Matthews, R.B., Kropfr, M.J., Bachelet. D. and Van Laar, H.H., 1995. The impact of glohal climate change on rice production in Asia: a simulation study. CAB International. Wallingford and IRRI, Los Baños. Philippines, in press.

Orchard, T.J. 1975. Calculating constant temperature equivalents. Agric. Meteorol., 15. 405-418.

Roberts. E.H. and Summerfield. R.J.. 1987. Measurement and prediction of nowering in annual crops. In: J.C. Altherton (Editor). Manipulation of nowering. Butterworths. London, pp 17-50.

Robertson. G.W., 1968. A biometeorological time scale for a cereal crop involving day and night temperature and photoperiod. Int. J. Biometeorol. 12: 191-223.

SAS (Statistical Analysis Systems Insthute, Inc.), 1988. SAS User's Guide: Statistics, Version f(M4 SAS. Cary. NC. 1028 on

Sharpe, P.J H. and DeMichele, D.W., 1977. Reaction kinetics of poikilotherm development J. Theor. Biol.. 64: $649-670$.

Summerficld. R.J , Collinson, S.T., Ellis, R.H., Rohers, E.H. and Penning de Vries, F.W.T., 1992. Photothermal responses of nowering in rice (Oryat satica). Ann. Bot., 69: 101-112

Tanaka, I.. 1976. Clinatic influence on photosynthesis and respiration of rice. In: Climate and rice. IRRI, Los Baños. Philippines, pp. 22.3-24.5 
Tollenaar, M., Daynard, T.B. and Hunter, R.B., 1979. Effect of temperature on rate of leaf appearance and flowering date in maize. Crop Sci., 19: 363-366.

Tyldesley, J.B.. 1978. A method of evaluating the effect of temperature on an organism when the response is nonlinear. Agric. Meteorol., 19: 137-153.

Watts, W.R., 197I. Role of temperature in the regulation of leaf extension in Zea mays. Nature, 229: 46-47. 